\title{
Environmental and Nutritional Consequences of Population Growth: A Sociological Appraisal of Asia
}

\author{
Mohammad Taghi Sheykhi* \\ Alzahra University, Iran
}

*Corresponding author: Mohammad Taghi Sheykhi, Professor of Sociology, Department of Social Science, Alzahra University, Iran.

\begin{abstract}
Climate change, industrialization, environmental change and increasing urbanization all together have impacted food products, increasing food consumption and in many cases food insecurity. Under such circumstances emerging challenges, nutrition shortages as well as population migration are widely observed within the dry lands of the developing world with special reference to Asia. In recent years, these topics have come to the center of attention of policymakers, and the community of scholars studying these phenomena. The above interwoven phenomena have largely affected food accessibility in many parts of Asia. As a result of such a scenario, shortage of food is widely observed, and prices constantly rise. Such a situation increases poverty and lower purchasing power for an increasing number of people. To remedy the crisis, these countries need effective policies with respect to agriculture, environmental management, settlements, urbanization, and population dynamics.
\end{abstract}

Keywords: Environment; Nourishment; Population growth; Vulnerability; Urban management

\section{Introduction}

Meeting the basic human needs of growing population is dependent on a healthy environment and nutrition. At the same time, many of the environment and development challenges, including the economic and social dimensions of sustainable development, such as poverty, consumption, human health and human settlement are the consequences of population growth and high fertility rate, especially in the Third World context. Pressure on the environment may result from rapid population growth, distribution, and migration, especially in ecologically vulnerable eco-systems. Urbanization and policies that do not recognize the need for rural development also create environmental problems. Likewise, demographic factors, combined with poverty and lack of access to resources in some areas, and excessive consumption and wasteful production patterns in others, cause or exacerbate problems of environmental degradation, resource depletion, poverty of nutrition and thus inhibit sustainable development. Several key terms such as degradation of agricultural land, destruction of forests, loss of biological diversity, over-use and misuse of freshwater etc. demonstrate the important link between human population and the resources need to sustain them. Though land degradation is currently a global problem, yet, it is becoming acute in many areas of the developing world, where population pressures are observed.

\section{Sources of Threat}

The global environmental threats are of several sorts, that is: the creation of waste which cannot be disposed of in short term or recycled, pollution, and the depletion of resources that cannot be replenished; all of which lead to significant environmental and nutritional problems. When environmental analysts speak of waste materials, however, they mean not only goods that are thrown away, but gaseous wastes pumped into the atmosphere too. Several such wastes are giving rise to serious global concerns such as carbon dioxide produced out of oil, coal, and gases released into the air by the use of aerosol cans, material for insulation and air conditioning units etc. Also, due to the expansion of modern industries worldwide, there are climbing demands for sources of energy, raw materials and food. Yet, the world's supply of such energy sources and raw materials are obviously limited. While the known oil resources of the world can be completely consumed by the year 2050, new resources/ reserves of oil will be discovered, or alternative sources of energy will be invented, and put into use [1]. 
Therefore, rescuing the global environment will be possible, simply through social and technological change.

\section{Aims of the Study}

The aims of the present study are to find out:
a. Vulnerability of the environment.
b. Hazards of high population growth.
c. A population, environment and nutrition equilibrium.

\section{Hypotheses}

a. Rapidly growing populations can increase the pressure on resources.

b. High population growth can slow the rise in living standards.

c. High population growth can degrade the social, environmental and nutritional conditions.

\section{Methodology}

To make a scientific, unbiased and logical research, suitable methods must be adopted. The following methods and procedures have been applied in order to prepare the paper, and eventually reach adequate results. It is hoped that in the course of the present study some of the environmental and nutritional problems of Asia would be recognized as follows:

\section{Scope of study}

By the scope, we mean the specific areas of the study. The main scope of the intended study is:

1. The Third World's demographic, environmental and nutritional conditions in the 21st century in general, and that of Asia in particular will be studied.

2. Vulnerability of the relevant nations in demographic, environmental and nutritional dimensions will be conducted.

3. Presentation of some guidelines on the phenomenon will be studied.

\section{Tools of data collection}

Various techniques and tools of data collection are very important in a research. In the research related to the present study, the following tools have been used:

1. Books, documents, records and relevant electronic sources of information.

2. Observation: The researcher used this method too, through visiting various Asian societies, and through following their developments over the course of time, and necessary information was elicited.

3. Interview: To find out right and relevant information, some informants and specialists on the subject were contacted.

\section{Population, Environment and Nutrition}

\section{A general perspective}

The future of humanity and that of the environment are tightly intertwined and both depend on population growth and population quality. Human beings have colonized some two-thirds of the world's land, and most of the rest is either inaccessible or unproductive mountaintops, forests, ice caps, tundra, or desert [2]. Technological advances are sometimes described as "freeing" humanity from dependency on nature, but this global takeover has made humankind dependent on the physical environment in new ways, and the process has threatened that very environment. Population increase is known to be one of the main causes/ threats to the environment and nourishment. It is important to bear in mind that high levels of population are not the only way in which we put stress on the earth's economy, that is the pattern of relationships between organisms (including humans) and between organisms and their environments. Environmental degradation is not only caused by the population growth in the Third World, consumers in the First World too, have a decisive role. Consumers in the world's rich countries put far more than their share of strain on the earth by demanding abundant energy and foods (like beef) whose production uses up enormous amounts of waste, much of it hazardous and injurious to the environment. The earth is challenged not just by how they live. Westerners are blamed too, to be responsible for the environmental degradation. As it is said; A small number of car-driving, beef-eating, waste-producing of the First World, especially Americans pumping water long distances, and using air conditioning, so they can live comfortably in the desert, may do more ecological damage than ten times as many poor people in the Third World.

Nonetheless, large populations are a source of environmental and food problems and a strain on resources. Even at a low level of technology, a swelling population is likely to strip land of its forests largely for fuel. Worldwide, the magnitude of ecological challenge is staggering mainly due to over-population, that is to say: Every second over 200 tons of carbon dioxide pour into atmosphere and 750 tons of top soil are lost affecting food production. Each day 47000 hectares of forests are destroyed; 345000 hectares of lands are turned into desert and probably as many as 300 species become extinct. Perhaps the best example of tension between population growth and resource allocation has to do with food supply. In this regard, about 1 billion of the earth's 7.621billion population less more than to eat [3]. Approximately a third of the world's grain is fed to livestock so that the well-to-do, most of whom living in the rich countries of the First World, are supplied with meat, eggs and dairy products. Perhaps 3 billion more people get enough to eat, though their diets are primarily vegetarian. That leaves nearly a billion people who are chronically hungry, and as many as 400 million who are so undernourished that their health is threatened, or their growth is stunted. Severe hunger is concentrated in the Third World, especially in Latin America and Africa. Almost the continuous famine in the Sahel, the area just south of the Sahara, is virtually the Malthusian nightmare coming true. Over-population led to excess grazing, cultivation, and water pumping; combined with civil war, it resulted ultimately in mass starvation. In 1980s, one out of every five children born in this region, namely 5 million infants died each year from hunger-related causes. (Independent Commission on International Humanitarian Issues, 1985). From 1950 to about 1984, worldwide grain production increased steadily (though distribution was uneven). The main reason for this change 
was the Green Revolution, because of which cereal crops such as corn, wheat and rice doubled or tripled per acre land. India and Pakistan have been reported involved in these high-yielding grains which have been hailed as the solution to world hunger. The Green Revolution did produce spectacular short- term grain, but at the price of long-term damage to the environment. On the one hand, Malthusians blame the environmental damage as a result of unpleasant population growth. On the other hand, the AntiMalthusians blame everything but population for the environmental damage. They blame everything but population, viz, affluence in the North, poverty and inequality in the South, inappropriate technology, war, misguided policies etc. while assessed, population is counted as a secondary factor [4].

On the basis of the theory put forward by the Environmentalist Barry Commoner: "environmental quality is largely governed not by population growth, but by the nature of the technologies of production". However, his examples show that population growth is responsible for between 24 and 31 percent of the environmental impact. An effect of that magnitude is significant enough to make population growth at least one of the measures worth adopting to cut pollution, and thereby prevent the environment from being damaged and hunger to be controlled. According to estimations done, population growth accounts for 62 percent of the increase in co2 emissions, while consumption and technology factors together account for only 38 percent. Pollution which is responsible for environmental problems is the result of taking something away such as deforestation, loss of species, soil erosion, loss of land to urbanization and the like. Loss of species is directly related to loss of habitat area. So, in this over-simplified case, population growth is the sole cause. Also, in case of high population growth, and high demand for fuel, building materials and cultivating farms, forests and green space are lost. In the same way, over-cultivation on lands to yield more crops cause soil erosion which is a great damage to the environment and food supply. Growing population also need extra land for nonagricultural uses such as housing, roads, factories, offices, playgrounds, parks etc. Since towns usually grow in agricultural areas rather than deserts or forests, this "other" land is taken away from farm land. Farmers must either intensify further or make up their losses by clearing more woodland and forest. There is another view that, it makes no sense to focus on population programs as the main means of combating degradation in the present, however. Changes in lifestyles, consumption, technology and land reform, and reduction of rural poverty, all will have the greatest immediate impact. The truth is that we need to act on all fronts simultaneously. Environmental problems, their levels of impact, causes and effects can be misleading. These issues and options are not discrete; environmental problems are often intertwined, as are their causes. Consequently, an adequate framework for urban and rural environmental management is needed, because it considers the interrelationships between not only problems, but solutions as well.

\section{Urban Management, the Environment and Nutrition}

Environmental strategies for cities must be so set as to run according to the needs and conditions. Environmental strategies must cover urban waste management and pollution control, energy and environment linkages in the urban sector, regulatory and economic instrument for pollution control, environmental dimensions for urban land use, and the urban environmental planning and management process; each is designed to provide background information on key urban development-environment linkages, and/or suggest elements of an environmental management strategy for cities in the developing world. Reports must be periodically prepared, and research continuously done on:

1. The health impacts of urban environmental problems,

2. The economic valuation of urban environmental problems,

3. The application of remote sensing and geographic information systems to urban environmental and food planning,

4. Urban environmental data collection,

5. The local management of hazardous wastes from small and cottage industries.

Operational strategies must be set, and suitable supervision must be focused on the all above policy initiatives. While designing strategies, many departments including the Organization for Environment Protection must keep a constant watch on the civil society, and somehow or the other conceptualize it as a symbol of civilization. To be successful in having a healthy environment, we should call for a single environmental monitoring and assessment agency to enforce environmental standards, and to work with industry and local communities. My message is that every country of the region including Iran can either turn toward environmentally sustainable economic growth or choose an environmentally destructive path as the pressure for land, housing and jobs builds up more due to unbridled population growth three decades back.

\section{Poverty and Environment}

It is obvious that a degraded environment has direct impacts on human health and welfare. The poorest countries in the world, being concentrated in Africa, Asia and Latin America suffer from different forms of poverty, high rate of infectious and parasitic diseases, and malnutrition. Under such health and poverty conditions, high infant mortality rates are accompanied by low life expectancy at birth. Health services whether curative or preventive, rarely reach the very poor in developing countries whose population growth is high in either rural or urban areas. The same applies to the basics of environmental health, namely clean water and sanitation, adequate food and shelter. Poverty, the most serious threat to health in developing countries, accompanies all the common factors which account for a high incidence of disease. Even in industrialized countries, the children of the poor are twice as likely to die as those in the highest socio-economic groups. The effect is multiplied in the poorer countries. Poverty has a large extent due to population growth. According to the eco-demographic studies done by (UNEP), about one-fifth of the world's 7.6 billion people live in absolute poverty, and as enunciated in the "Fourth World Conference on Women" Beijing September 1995, 70 percent of the world's poor are women whose main factor is the high population growth. This percentage is even higher in the least-developed countries (LDCs) [5]. 
Poverty and economic insecurity are also the wellsprings of migratory movements. Surveys have shown that despite poverty, lack of satisfactory jobs, and the absence of decent housing, urban advantages are real, and many migrants say they prefer poverty in city to rural deprivation and desperation. Such a movement also brings extensive degradation of environment. Historically, migration has produced social and economic benefits for all concerned, but the movement of millions of people annually now strains the environment, especially the host one. Therefore, a slowdown in world population growth is a key requirement for reducing the massive and increasing human migration across the world, and thereby to safeguard the environment and nourishment.

\section{Population and Growth vs Quality of Life}

Quality of life is the criterion to-day to represent how far a society/region is developed so far as its standard of living in general is concerned. The index of quality of life measures development in its broadest sense. The criteria of which are not only income or per capita gross domestic product GDP, but life expectancy, health, literacy, school enrolment, food security, wealth distribution, military expenditures, population growth rates, fertility levels, contraceptive prevalence rates, the state of natural resource stocks etc. are included in it. A significant reduction in population growth rates is absolutely essential if improvements in the Third World standard of living in general and that of Asian context in particular is expected. As population growth has outpaced development contexts, the following criteria reflect the link between population on the one hand, and nutrition, development and environment on the other, namely:

\section{Health}

Despite improvements in access to medical care and family planning services, there is still a wide gap in health care between the developed and developing regions of the world. Around 13 million children under the age of 5 die every year, many of whom from preventable causes linked to polluted environments. In the developing world as a whole, infant mortality rate averages 81 per 1000 live births, compared to 23 in developed countries. In the most environmentally degraded region of Africa, it is 114 deaths per 1000 live births. Another important though indirect cause of infant mortality is poorly-spaced birth, often due to a lack of family planning services. As found out through the UN estimates, children born less than two years after the previous child, stand at 66 per cent chance of dying in infancy. Even if these children survive, their vulnerable early years, namely their growth is more likely to be stunted, their intellectual development impaired, and their prospects for adult life greatly diminished. In addition to this, more complications are due, under the conditions of illegal abortions in these countries.

\section{Employment}

Due to the rapid population growth and rural-urban migration, the developing world including Asia is fast approaching a "human development crisis", simply because of young people entering the job market during the decades of the 1990s and 2000. Hence, the developing countries must create, on average 30 million new jobs every year just to prevent present rates of unemployment and under employment from worsening. As estimated, there are now around 2 billion people in the Third World either working or looking for work; a number that will swell to 3.1 billion by the year 2025. Already, those totally unemployed or underemployed is over half a billion in the Third World; a number nearly equivalent to the entire workforce in the industrialized world.

\section{Landlessness}

This phenomenon together with land fragmentation is already a widespread problem throughout the developing world. It is particularly acute in South and Southeast Asia. For example, on the basis of the studies done, nearly 10 percent of all Thai households were landless in 1984, with many cultivating only an eighth of a hectare. Therefore, shortages of land contributed to the destruction of much of Thailand's rich tropical hard wood forests in the northern and northeastern parts of the country, the consequences of which has been environmental and food degradation.

\section{Urbanization}

One of the most dominant trends of the late 20th century is the phenomenal growth of urban areas. It is one of the most extreme demographic phenomena since people started gathering in cities 5000 years ago. In 1950, only 18 percent of humankind lived in urban communities, whereas at the turn of the century the proportion is approaching 50 percent. By far, the greatest increase is occurring in the developing world. That is to say, the under 2 billion urban residents of 1990 in the developing world will jump to almost 4 billion by the year 2025. This phenomenon will lead to various socio-environmental and nutrition problems.

\section{Poverty}

The number of absolute poor is now over 1 billion and still growing. As estimated, nearly 770 million of them are chronically malnourished. Obviously, high fertility rates, rural-urban migration, and youthfulness of the Third World population directly or indirectly contribute to such a phenomenon. Their economies would deteriorate under the triple burden of heavy debt, dwindling natural resources, and unfair terms of trade. According to population scientist [6], "Population growth prevents the development that would slow population growth".

\section{Water pollution}

Population pressures and the misuse of water resources not only reduce water supplies but decrease water quality as well. This situation is followed by environmental degradation and waste. The whole scenario is eventually faced with the prospect of environmental and food refugees.

\section{The case of iran}

According to 2016 population and housing census of Iran (Census, 2016) [7], in mid-2016, the population of the country was estimated to be 80 million and growing at a rate of less than 1.5 percent per annum. The population is very unevenly distributed, with main concentrations being in Azarbayejan, the Caspian region, and the western part of the country. Rural to urban migration is one of the main factors of Iran's environmental and food degradation. However, the absence of proper organization and management, and 
the unchecked and unplanned migration of the rural population to urban areas, usually results in the creation of a poor population, and the formation of slums in urban areas. Therefore, it is important for the government to play a more efficient role in the management of rural to urban migrants, so that it could be carried out in a planned, organized and orderly manner. In this way the environment could be protected. Sociologically speaking, in case of Iran, rural to urban migration in overall context is considered to be poverty alleviating and thereby environment-polluting. However, it is believed that migration to urban areas is not a proper solution to rural poverty, but it enunciates that the existing gap between rural and urban areas in terms of social and economic indicators to be narrowed through mechanisms such as investing in food production, health, education, human resources (development), employment creation, infra-structure of development and housing etc., especially with reference to rural areas. The growing volume of motorized movement is inflicting yet further damage on environment, that is, poor traffic management, old and badly-conditioned and serviced vehicles combined with traffic jams to inflict the greatest damage on air quality, especially in hot sunlight. Hence, well-urban management can provide efficient system to manage flows: people, goods, services, information and finance in the cities, and the reverse will create a poverty trap in which poor transport system also plays a major part. That is to say, in order to have an environment free of pollution, a well-planned transport system within the city/ town may achieve an opimum role of circulation of people, goods etc. Another major problem of the metropolitan areas with reference to Iran is smog. Besides being a health hazard, it is sometimes so thick that visibility gets reduced and breathing for the elderly very dangerous. Many big cities in the country such as Tehran, Arak, Mashhad, Tabriz, etc. are currently environmentally problematic.

\section{Sociological Over-View}

The ecological perspective of the country remains influential in urban sociology today. As one part adapts to a changing environment, adjustments are needed in other parts, so that the whole remains vital. For instance, when a certain district of the city is invaded by manufacturing and heavy transport, nearby areas will develop working class housing for the workers that new factories need; and sometimes consequently slums are grown. Note that these manufacturing and residential districts are mutually beneficial and interdependent. The factories need workers, and provide them with jobs, and for those who are very dependent on transportation means, they too need factories, which are dependent on labor. In this functional view, regions and cities constantly adapt so as to improve their chances of survival in certain environment [8]. Under the conditions of population growth in Asia, urban ecologists and sociologists see the development of cities as a more or less natural process of adaptation to changing social and technological environment which is very dependent on transport system too. Due to population growth, environment which includes the conditions, circumstances and the surroundings, affects the development and growth of an organism or the cells within this process which eventually affects and the ecosystem, and the sociocultural values in the society too [9-21].

\section{Solutions to the Problem}

1. Development can be pursued, and environment protected only if population size and growth are in harmony with the changing productive potential of the ecosystem.

2. Governments especially those in the Asian region should develop long-term, multi-faceted population policies and campaigns to pursue broad demographic goals.

3. Managing demographic change and pressures.

4. Achieving food self-sufficiency and food security.

5. Ensuring efficient and equitable use of water resources.

6. Securing greater energy self-sufficiency.

7. Optimizing industrial production.

8. Preventing desertification.

\section{Conclusion}

Degradation of natural resources and environment, and the loss of productive lands can be reversed in Asia only through increased and more effective cooperation between different sectors of a society as well as between countries. This will be particularly important in introducing environmentally safe industrial development, and slowing rapid population growth, especially with reference to the growth of giant cities. With care and attention, and sustainable development in the international community, governments, industry, and all levels of society, the earth could manage and would be capable of responding the increasing needs of the new century. It is already clear that no country or group is immune from danger; that is to say, all countries and individuals, rich or poor, developed or developing, can be important agents both of conservation or of destruction, depending on choices they make, and the policies they adopt. Through following such a path, environment, food and population growth could come into balance and harmony. Quality of life also could be safeguarded only if the afore-said balance is achieved. Iran too, must follow suit with the experiences of the more developed societies to check its population growth and simultaneously conserve its environment; immune from pollutants and food sufficiency which is a hard job to do.

\section{Acknowledgement}

None.

\section{Conflict of Interest}

No conflict of interest.

\section{References}

1. Giddens A (1994) Sociology. Polity Press, Cambridge, USA.

2. Paul RE, Anne HE (1991) The population explosion, Simon \& Schuster, New York, USA.

3. World Population Data Sheet (2018) PRB, Washington DC, USA.

4. Harrison Paul (1988) Inside the Third World, Mc Graw-Hill, London, UK

5. International Dateline, September 1995.

6. Rostow WW (1990) The Stages of Economic Growth, Cambridge University Press, London, UK. 
7. Population and Housing Census of Iran (2016) Statistical Center of Iran.

8. Webster A (1991) Introduction to the Sociology of Development, Macmillan, London, UK.

9. Castells Manuel (1998) The End of Millennium, Blackwell, Oxford, USA.

10. International Development Research Center (IDRC) Reports, April 1995.

11. Katyal S (1993) Environmental Pollution, Anmol Publications, New Delhi, India.

12. Keller S (1994) Sociology, Mc Graw-Hill. Inc, New York, USA.

13. Marsh Ian (2000) Sociology, Prentice-Hall, Essex, UK.

14. Population, NO.3, UNFPA, 1990.
15. Population and Development Review (1995), Population Council, New York 21(1).

16. Population and the Environment (1991) The Challenges Ahead, UNFPA, UN Publications.

17. Population Headliner (1996) No. 254 ESCAP Publications, Bangkok, Thailand.

18. Rapid Urban Environmental Assessment (1994) World Bank.

19. Safeguarding the Future (1993) UNFPA.

20. Wald Mattew (1990) Guarding the Environment, New York Times, NY, USA.

21. World Population Data Sheet (1990) PRB, Washington DC, USA. 